\title{
Use of "one-pot, mix-and-read" peptide-MHC class I tetramers and predictive algorithms to improve detection of cytotoxic T lymphocyte responses in cattle
}

\author{
Nicholas Svitek ${ }^{1 *}$, Andreas Martin Hansen², Lucilla Steinaa', Rosemary Saya ${ }^{1}$, Elias Awino ${ }^{1}$, Morten Nielsen,
} Søren Buus ${ }^{2}$ and Vishvanath Nene ${ }^{1 *}$

\begin{abstract}
Peptide-major histocompatibility complex ( $\mathrm{p}-\mathrm{MHC}$ ) class I tetramer complexes have facilitated the early detection and functional characterisation of epitope specific $C D 8^{+}$cytotoxic $T$ lymphocytes $(C T L)$. Here, we report on the generation of seven recombinant bovine leukocyte antigens (BoLA) and recombinant bovine $\beta 2$-microglobulin from which $\mathrm{p}-\mathrm{MHC}$ class I tetramers can be derived in $\sim 48 \mathrm{~h}$. We validated a set of $\mathrm{p}-\mathrm{MHC}$ class I tetramers against a panel of CTL lines specific to seven epitopes on five different antigens of Theileria parva, a protozoan pathogen causing the lethal bovine disease East Coast fever. One of the p-MHC class I tetramers was tested in ex vivo assays and we detected T. parva specific CTL in peripheral blood of cattle at day 15-17 post-immunization with a live parasite vaccine. The algorithm NetMHCpan predicted alternative epitope sequences for some of the T. parva CTL epitopes. Using an ELISA assay to measure peptide-BoLA monomer formation and p-MHC class I tetramers of new specificity, we demonstrate that a predicted alternative epitope $T p 2_{29-37}$ rather than the previously reported $T p 2_{27-37}$ epitope is the correct Tp2 epitope presented by BoLA-6*04101. We also verified the prediction by NetMHCpan that the Tp5 $87-95$ epitope reported as BoLA-T5 restricted can also be presented by BoLA-1*02301, a molecule similar in sequence to BoLA-T5. In addition, Tp5 $87-95$ specific bovine CTL were simultaneously stained by Tp5-BoLA-1*02301 and Tp5-BoLA-T5 tetramers suggesting that one T cell receptor can bind to two different BoLA MHC class I molecules presenting the Tp5 $5_{87-95}$ epitope and that these BoLA molecules fall into a single functional supertype.
\end{abstract}

\section{Introduction}

$\mathrm{CD}^{+}$cytotoxic $\mathrm{T}$ lymphocytes (CTL) play a significant role in controlling intracellular pathogens such as viruses and parasites through a perforin/granule mediated cytolytic mechanism, Fas-induced apoptosis or by release of IFN- $\gamma$ [1]. The specificity of CTL is mediated by their T-cell receptor (TCR) which recognize foreign peptide epitopes associated with major histocompatibility complex (MHC) class I molecules at the surface of infected cells (reviewed in [2]). The antigen specificity of CTL is commonly measured using synthetic peptide epitopes in IFN- $\gamma$ ELISpot or cytolytic assays. However, the demonstration that soluble

\footnotetext{
* Correspondence: n.svitek@cgiar.org; v.nene@cgiar.org

${ }^{1}$ International Livestock Research Institute (ILRI), P.O. Box 30709, Nairobi 00100, Kenya

Full list of author information is available at the end of the article
}

peptide-MHC (p-MHC) class I complexes will bind to TCR has led to generation of multimeric forms of p-MHC class I tetramers as diagnostic reagents that can be used to detect and purify epitope specific CTL. The importance of these reagents in research is highlighted by the creation of a NIH Tetramer Core Facility, which provides to the scientific community pre-made and made-to-order p-MHC class I tetramers for a number of human, mouse, macaque and chimpanzee MHC alleles, including class I, class II and non-classical MHC molecules. Many p-MHC class I tetramers are now also commercially available. However, such tools are in general not available for livestock species.

Peptide-MHC class I complexes are hetero-trimeric in nature consisting of the MHC class I molecule, often referred to as the heavy chain ( $\mathrm{HC})$, a peptide of eight to eleven amino acids in length and an invariant molecule 
called $\beta 2$-microglobulin $(\beta 2 \mathrm{~m})$ (reviewed in $[3,4]$ ). Generation of the $\mathrm{p}-\mathrm{MHC}$ class I complex in vivo involves many steps and is tightly regulated by chaperones [5]. Peptides are generated by the proteasome, a multicatalytic complex in the cytoplasm that cleaves proteins into polypeptides [6], which are further processed by ER-luminal peptidases [7] during peptide loading onto MHC class I molecules by the peptide-loading-complex [8] prior to export to the cell surface. However, it is possible to generate p-MHC class I complexes at high efficiency in vitro [9-13] by co-incubation of recombinant MHC class I HC, synthetic peptide and recombinant $\beta 2 \mathrm{~m}$. The affinity of peptides that bind to the peptidebinding groove in the $\alpha 1-\alpha 2$ domain of the $\mathrm{HC}$ is primarily dictated by the identity of amino acids at "anchor positions" and sequence motifs describe peptides that fit into a particular peptide-binding groove [14]. Sequence polymorphisms in this region of the $\mathrm{HC}$ result in different peptide binding specificities and motifs, which mediate the functional differences between different MHC class I molecules [15]. These observations have led to the generation of several algorithms ([16-18], for a detailed review see [19]) that attempt to predict the presence of CTL epitopes in proteins.

Different methods have been developed for generating multimeric peptide MHC complexes [13,20,21]. Here we describe the use of the system of Leisner et al. [11] for production of bovine leukocyte antigen (BoLA) p-MHC class I tetramers to facilitate the study of immune bovine CTL as part of our subunit vaccine development program against East Coast fever (ECF), a lethal disease of cattle in sub-Saharan Africa. The disease kills about one million animals each year with severe negative socio-economic impact on the smallholder farmers and pastoralists whose livelihoods depend on their animals [22,23]. Animals that recover from infection are solidly immune to re-infection and this observation led to development of a live parasite based infection and treatment method (ITM) of vaccination against ECF [24]. The immunity induced by ITM is primarily dependent on parasite-specific CTL and is parasite strain specific. Vaccination with mixtures of parasite broadens the spectrum of immunity $[24,25]$ and such a vaccine, called the Muguga cocktail, which consists of three different parasite isolates, is available on a commercial basis in some countries [26]. However, there are several problems with the live vaccine as it requires a liquid nitrogen cold chain for delivery, oxy-tetracycline treatment and is expensive ( $\$ 8 \sim 12 /$ dose). Hence, the availability of a subunit vaccine with a better product profile than the current vaccine is likely to benefit programs targeting the control of ECF.

A feature of the protective CTL response generated by ITM is that it is focused on a limited number of epitopes, the identity of which is influenced by the BoLA genotype of individual animals and the strains of the parasite used for immunisation [27]. The antigen and epitope specificity of CTL induced by the Muguga isolate of T. parva and restricted by ten different BoLA class I molecules in cattle has been reported [28,29], and unpublished data]. Identification of these T. parva CTL epitopes was carried out in a two stage process, first through screening of parasite cDNA to define relevant antigens and then through screening of synthetic overlapping peptides to define epitopes within the predicted antigen sequence [29]. Although 12 CTL epitope sequences were defined they were primarily evaluated in IFN- $\gamma$ ELISpot assays and most were not subjected to systematic analyses to determine minimal epitope sequences. We previously evaluated NetMHCpan, a pan-predictor of CTL epitopes to assess the T. parva epitopes. In general we found that the predictive power of the algorithm for the known CTL epitopes was high, although the method in some cases predicted the presence of alternative epitope sequences of stronger affinity [30].

Here we report on generation of $\mathrm{p}-\mathrm{MHC}$ class I tetramers based on a set of seven different recombinant BoLA MHC class I molecules for detection of CTL responses to epitopes located in five different $T$. parva antigens and the use of one p-MHC class I tetramer in ex vivo assays. A critical feature of the Leisner system is that new p-MHC class I tetramers can be made on demand with a turnaround time of $\sim 48 \mathrm{~h}$, which as described herein accelerates the ability to test candidate epitopes and define new CTL specificities. Based on predictions from NetMHCpan and MHCcluster we provide experimental evidence that redefines a CTL epitope on antigen $\mathrm{Tp} 2$ and that an epitope on antigen $\mathrm{Tp} 5$ can be presented by two closely related but distinct BoLA MHC class I molecules.

\section{Material and methods}

\section{Expression and purification of BoLA class I HC and $\beta 2 \mathrm{~m}$ molecules}

The expression and purification of biotinylated BoLA class I HC molecules was performed essentially as described in [11]. Briefly, truncated versions of the BoLA class I HC without their trans-membrane domain and containing a biotinylation tag (BSP) were cloned into pET28a+. The proteins were expressed in E. coli BL21 (DE3) co-transformed with a pASYC vector encoding the BirA enzyme, which increases the efficiency of biotinylation of the BSP tag. Expression of $\mathrm{HC}$ and BirA was induced by adding IPTG $(1 \mathrm{mM})$ during the last $3 \mathrm{~h}$ of culture. Biotin (Sigma, $100 \mathrm{mg} / \mathrm{L}$ ) was added to the culture prior to inducing protein expression. Large-scale production and purification were performed as previously described [31]. Briefly, this involves culture of $E$. coli BL21 (DE3) in ECPM 1 media [32] using 2-L Labfors fermenters (Infors AG). Cell lysis was performed by high-pressure cell disruption (Z PLUS, Constant Systems, Daventry, UK). Inclusion bodies were collected by centrifugation at $17000 \mathrm{~g}$ for $10 \mathrm{~min}$ at $4{ }^{\circ} \mathrm{C}$. 
Washed inclusion bodies were solubilized in $20 \mathrm{mM}$ Tris$\mathrm{HCl}$ (pH 8.0) and $8 \mathrm{M}$ urea. $\mathrm{HC}$ molecules were purified in 8 M Urea first on Q-Sepharose (Amersham Biosciences) then on phenyl-Sepharose column (Amersham Biosciences) and high molecular complex aggregates were removed by size exclusion chromatography on Sephacryl columns. Bovine $\beta 2 \mathrm{~m}$ molecule was purified using the same method as for human and porcine $\beta 2 \mathrm{~m}[31,33,34]$. Briefly, recombinant bovine Met- $\beta 2 \mathrm{~m}$ was dissolved in $8 \mathrm{M}$ urea and purified on Q-Sepharose; refolded overnight by drop-wise dilution into $25 \mathrm{mM}$ Tris, $300 \mathrm{mM}$ Urea, $\mathrm{pH} 8$; concentrated by tangential flow ultrafiltration (Vivaflow); and buffer-exchanged into PBS by gel filtration (Superdex 200, Amersham Biosciences). Finally, the product was concentrated and frozen at $-20{ }^{\circ} \mathrm{C}$ until use.

\section{Production of peptide-MHC class I tetramers}

Peptide-MHC class I tetramers were generated as described previously [11]. Briefly, purified BoLA HC at a final concentration of $0.25 \mu \mathrm{M}$ was incubated with the following: $\beta 2 \mathrm{~m}[1.5 \mu \mathrm{M}]$, peptide [4 $\mu \mathrm{M}]$, EDTA $(1 \mathrm{mM})$, pepstatin A $(1 \mu \mathrm{M}), 1.10$ phenantroline $(100 \mu \mathrm{M})$, TLCK $(50 \mu \mathrm{g} / \mathrm{mL})$, TPCK $(100 \mu \mathrm{M})$, PMSF $(100 \mu \mathrm{M})$, Lutrol (0.03\%), $50 \mathrm{mM}$ of Tris-maleate (pH6.6), in a final volume of $500 \mu \mathrm{L}$. Incubation was performed at $18{ }^{\circ} \mathrm{C}$ for $48 \mathrm{~h}$ and then high molecular weight complexes were removed by centrifugation with an Amicon ${ }^{\circ}$ Ultra Centrifugal Filter Units $(0.5 \mathrm{~mL} / 100 \mathrm{~K})$ [cat no. UFC510024] at $14000 \mathrm{~g}$ for $10 \mathrm{~min}$. The flow through was recovered and the p-MHC class I complexes were tetramerized at room temperature by incubating them with $1.5 \mu \mathrm{g}$ of phycoerythrin (PE)streptavidin (BD Pharmingen, cat no. 554061) or allophycocyanin (APC)-streptavidin (BD Pharmingen, cat no. 554067) starting with $0.45 \mu \mathrm{g}$ and then adding $0.21 \mu \mathrm{g}$ every ten min over a $50 \mathrm{~min}$ period at room temperature and then stored at $4{ }^{\circ} \mathrm{C}$.

\section{Synthetic peptides}

Peptides were purchased from Mimotopes (Victoria, Australia) at a purity of $95 \%$ and re-suspended in water containing $0.1 \%$ acetic acid at a final concentration of $10 \mathrm{mM}$ and diluted to working concentrations in sterile water. The sequences of $T$. parva peptide epitopes are as in Table 1. A control known peptide sequence that binds to BoLA-6*01301, YMYRVWSPL, was determined from a bank of random nonamer peptides by a binding assay as described in [34]. The sequence of the control peptide for BoLA-3*00101 is the Tp4 CTL epitope (TGASIQTTL) which is a known binder to BoLA-3*00101 [29].

\section{ELISA assay to measure peptide-MHC class I monomer formation}

Folding of p-MHC class I complexes was assessed with an ELISA assay as described in [35]. The BoLA-6*04101
Table 1 List of bovine immunological reagents

\begin{tabular}{|c|c|c|c|}
\hline $\begin{array}{l}\text { Restricting BoLA } \\
\text { class I molecule }\end{array}$ & CTL Lines & $\begin{array}{l}\text { T. parva } \\
\text { antigen }\end{array}$ & CTL Epitope \\
\hline 1) $6^{*} 01301$ & BB007 \& BV115 & Tp1 & ${ }^{214}{ }^{2} G Y P K V K E E M L_{224}$ \\
\hline 2) $6^{*} 04101$ & BW02 (Clones 5 \& 7) & Tp2 & ${ }^{27}$ SHEELKKLGML 37 \\
\hline 3) $2 * 01201$ & 592 & Tp2 & ${ }^{49} \mathrm{KSSHGMGKVGK}_{59}$ \\
\hline 4) $\mathrm{BoLA}-\mathrm{T} 2 \mathrm{C}$ & Bx196 & Tp2 & ${ }^{96} \mathrm{FAQSLVCVL}_{104}$ \\
\hline 5) BoLA-T5 & BV50 & Tp5 & ${ }^{87}$ SKADVIAKY $_{95}$ \\
\hline 6) $3 * 00101$ & $B \times 63$ & Tp8 & ${ }^{379} \mathrm{CGAELNHFL}_{387}$ \\
\hline 7) $1 * 02301$ & 495 & Tp9 & ${ }^{67}$ AKFPGMKKSK ${ }_{76}$ \\
\hline
\end{tabular}

The Table lists the BoLA class I molecules that were expressed in this study, the panel of CTL lines used to test p-MHC class I tetramers and their antigen and epitope specificity. The bulk CTL lines were prepared from cattle immunized with a live parasite vaccine as previously described [29]. The peptide specificity of each CTL line was confirmed by ELISpot assay (data not shown).

molecules $[0.25 \mu \mathrm{M}]$ and bovine $\beta 2 \mathrm{~m}$ molecule $[1.5 \mu \mathrm{M}]$ was incubated in a 96-well plate with $\mathrm{Tp} 227-37$ and Tp2 29-37 peptides at various peptide concentrations ranging from 0 to $40 \mu \mathrm{M}$. After an incubation of $48 \mathrm{~h}$ at $18{ }^{\circ} \mathrm{C}$, the complexes were transferred to another 96-well plate pre-coated with streptavidin (Nunc, cat\# 436014), which captures biotinylated $\mathrm{HC}$, and incubated for three hours at $4{ }^{\circ} \mathrm{C}$. After washing, the W6/32 monoclonal antibody (Santa Cruz Biotechnology, Texas, USA, cat \# SC32235), which binds to a monomorphic epitope on $\beta 2 \mathrm{~m}$ but only when it is incorporated in p-MHC class I complexes, was added for $1 \mathrm{~h}$ at $4{ }^{\circ} \mathrm{C}$. After washing, anti-mouse IgG coupled to peroxidase (Sigma Aldrich, cat \# A9917$1 \mathrm{ML}$ ) was added to the plate followed by incubation for an hour at room temperature and further rounds of washes. Colorimetric change was performed by adding the TMB Plus2 "Ready to Use" Substrate (Kem En Tec, cat \# 4395H) for $10 \mathrm{~min}$ at room temperature. The reaction was stopped by adding $\mathrm{H}_{2} \mathrm{SO}_{4}(0.3 \mathrm{M})$ and optical density was measured using an ELISA plate reader at $450 \mathrm{~nm}$. The concentration of $\mathrm{MHC}$ class I and $\beta 2 \mathrm{~m}$ molecules used in such assays is normally in the nanomolar range [35]. However, the bovine $\beta 2 \mathrm{~m}$ molecule used in this assay contains an extra methionine at the N-terminus that diminishes binding of the W6/ 32 antibody to the mature p-MHC class I complex, hence higher concentrations of recombinant molecules were used in the assay. We are in the process of generating a $\beta 2 \mathrm{~m}$ without the extra start methionine, which should allow use of recombinant molecules in the nanomolar range.

\section{Bovine CTL and parasite-infected cell lines}

CTL and autologous T. parva Muguga infected lymphocyte lines (TpM) were established as previously described [29] and maintained in RPMI containing 10\% fetal bovine serum [FBS] (decomplemented; Sigma), 1\% penicillin/ streptomycin, $1 \%$ L-Glutamine, $1 \%$ gentamycin, $0.1 \%$ betamercaptoethanol. CTL lines (Table 1) were propagated by stimulating them with irradiated autologous TpM at a ratio 
of 1:5 to $1: 10$ (CTL:TpM) and supplementing the media with $2 \mathrm{ng} / \mathrm{mL}$ of recombinant human interleukin (IL)-2 (Sigma) or $15 \%$ T-cell growth factor (TCGF). Cells were incubated at $37{ }^{\circ} \mathrm{C}$ in a $5 \% \mathrm{CO}_{2}$ humidified atmosphere. Clones 5 and 7 of the BW02 CTL line were obtained by limiting dilution.

\section{ELISpot assays}

IFNy ELISpot assays were conducted as described in [36]. Briefly, a monoclonal anti-bovine IFN $\gamma$ antibody (Serotec, Oxford, UK, cat.no. MCA1783) was incubated overnight at $4{ }^{\circ} \mathrm{C}$ on ELISpot plates (Millipore, Billerica, MA, USA) and then blocked with RPMI containing $10 \%$ heat-inactivated FBS for $2 \mathrm{~h}$ at $37{ }^{\circ} \mathrm{C}$. Peptides were added at $1 \mu \mathrm{M}$ concentration and CTL lines at $2.5 \times 10^{4}$ cells per well. The plates were incubated at $37{ }^{\circ} \mathrm{C}$ for $20 \mathrm{~h}$. Release of IFNy was monitored with primary rabbit polyclonal anti-bovine IFNY antibody (Sigma-Aldrich, St. Louis, MO, USA) and secondary AP-conjugated monoclonal anti-rabbit antibody (Sigma-Aldrich, St. Louis, MO, USA, cat \# A2556). Development of plates was done by addition of the substrate solution Sigma Fast (BCIP/NBT, Sigma-Aldrich, St. Louis, MO, USA).

\section{Flow cytometry}

Flow cytometry data were acquired on a BD FACSCanto ${ }^{\text {тм }}$ II instrument (BD Biosciences). Compensation controls for PE, PerCP, FITC and APC were included for automatic compensation by the FACS DIVA software. $10 \mu \mathrm{L}$ BoLA class I tetramer was used for staining cells (between $2 \times$ $10^{5}$ and $5 \times 10^{5}$ cells per sample). CD8 staining was done by incubating cells with ILRI monoclonal antibody ILA51 (IgG1) and using rat anti-mouse IgG1-PerCP (BD; cat \# 340272) as the secondary antibody. Staining for perforin was done using anti-human-perforin-FITC (BD Pharmingen, San diego, CA, USA, cat\# 556577) and staining for Fas-ligand was done using primary rabbit anti-Fas ligand (Santa Cruz biotechnology, cat no. SC-957) and secondary FITC-coupled anti-rabbit IgG antibody (Sigma, MO, USA, cat\# F-0382). All staining were conducted in PBS-0.5\% BSA except for intracellular staining with anti-perforin where cells were incubated and stained in PBS-0.1\%Saponin-10\% FBS. Negative control for intracellular staining was done with anti-dansyl-FITC antibody (BD Pharmingen, San diego, CA, USA, cat\# 556577). The data were analyzed using the FlowJo software version 7.6.5.

\section{Animal experiments}

Three cattle of BoLA-A18 haplotype (typed with PCR primers [forward] 5'-CCGGGATCCGAGGACT-3' and [reverse] 5'-CTCCATCTTGCGTTTGGA-3' specific for BoLA-6*01301) were vaccinated by ITM [24] using the T. parva strain Muguga 3308. Whole blood was collected from these cattle at the day of vaccination (day 0 ) and every two days till appearance of tetramer positive cells. PBMC were purified on Ficoll paque density gradients at $2500 \mathrm{rpm}$ for $25 \mathrm{~min}$ and $5 \times 10^{5} \mathrm{PBMC}$ were stained with the $\mathrm{Tp} 1_{214-224}$-BoLA-6*01301 tetramer as described in the flow cytometry procedure. This animal experiment was approved by the ILRI IACUC committee [\# 2012.10].

\section{NetMHCpan and MHCcluster}

We used NetMHCpan [37], a pan-specific predictor trained on known peptide epitope and MHC class I sequence data and the affinity of p-MHC class I interactions to predict $T$. parva epitopes. The binding affinity of selected epitopes was predicted using the latest version of NetMHCpan (version 2.8, [38]). Predictions of strong peptide binders was done by evaluating all possible eight to eleven-mers from antigens Tp2 and Tp5 with BoLA-6*04101, and BoLA-T5 and BoLA-1*02301 respectively. We also used MHCcluster [39] to compare predicted peptide-binding specificities between the different BoLA class I molecules involved in this study.

\section{Comparison of sequence similarities between BoLA-T5 and BoLA-1*02301}

BoLA-1*02301 and BoLA-T5 amino acid sequences were downloaded from the Immuno-Polymorphism Database [40-42] and NCBI respectively, and a MUSCLE alignment was done using clcSequence Viewer 6.0. Visualization of the position of the amino acid differences between these molecules was done on the crystal structure of BoLA2*01801 [43] using RasWin.

\section{Results}

\section{Generation of peptide-MHC class I tetramers and assay} on defined CTL lines

The "on-demand" Leisner system for tetramer generation involves p-MHC class I monomer formation in the presence of excess peptide (concentration of $4 \mu \mathrm{M}$ ), followed by tetramerization using either PE or APC labelled streptavidin (see Materials and methods). This method was used to generate a set of seven p-MHC class I tetramers from recombinant BoLA class I HC and bovine $\beta 2 \mathrm{~m}$ and synthetic peptides as listed in Table 1 . This system does not routinely measure monomer formation but this became necessary for some experiments (see below).

To verify the specificity of p-MHC class I tetramers we used T. parva-epitope-specific bulk CTL lines generated from ECF immune cattle as described in former studies $[28,29,44]$. To confirm the epitope specificity of the CTL lines, an IFN- $\gamma$ ELISpot assay was performed using the peptides described in Table 1. As expected all CTL lines were positive in this assay but only in the presence of their respective peptide epitope (data not shown). We then tested the specificity of the novel BoLA p-MHC class I tetramers 
to the different bovine CTL lines. First, we used the Tp1 $1_{214-224}$-BoLA-6*01301 p-MHC class I tetramer and BB007 CTL line to control for proper staining (Figure 1). As negative controls we used unfolded tetramerized $\mathrm{HC}$ (absence of peptides or an irrelevant peptide, Tp2 $2_{96-104}$, that does not bind BoLA-6*01301) and tetramerized HC folded with a control peptide, YMYRVWSPL, known to bind to BoLA-6*01301. The control peptide was derived from a bank of random nonamer peptides that bound with high affinity to BoLA-6*01301 (affinity equal to, or greater than, $1 \mathrm{nM}$ ). As shown, tetramers prepared with the control peptide (Figure 1B) displayed very low staining on the CTL when compared to the non-stained sample (Figure 1A). However, when CTL were stained with tetramers made without peptide or the irrelevant peptide we observed a low level smear staining of CTL (Figure $1 \mathrm{C}$ and $\mathrm{D}$ respectively), most likely due to nonspecific binding by unfolded HC. When the CTL were stained with a tetramer formed with the Tp1 peptide epitope we saw staining of a clear distinct cell population (Figure $1 \mathrm{E}$ ). Figures $1 \mathrm{~B}, \mathrm{C}$ and $\mathrm{D}$ suggest that non- specific staining of CTL is only observed in the absence of peptides that bind to $\mathrm{HC}$ and that minimal if any unfolded $\mathrm{HC}$ remain when binding peptide is in excess. Hence, the result in Figure 1E is significant.

Each of the remaining p-MHC class I tetramers was then tested against the CTL lines, including testing $\mathrm{Tp}_{214-224}$-BoLA-6*01301 p-MHC class I tetramers on a different CTL line, BV115. Distinct tetramer-positive populations were seen in cognate lines for 6 of the $7 \mathrm{p}$ MHC class I tetramers analysed, however, with great differences in the frequency of tetramer positive cells between the different cell lines. For example, about 3\% of cell line Bx63 stained positive with $\mathrm{Tp} 8_{379-387-\mathrm{BoLA}-}$ 3*00101 tetramers, while about $65 \%$ of cell line 196 stained positive with Tp296-104-BoLA-T2c tetramers (Figure 2). Non-specific staining was monitored using unfolded tetramers to differentiate with specific staining (data not shown). In some cases, p-MHC class I tetramer folded with control peptides known to bind BoLA-6*01301 and BoLA-3*00101 were used as further controls. The $\mathrm{p}-\mathrm{MHC}$ class I tetramers generated with BoLA-T5, BoLA-T2c and BoLA-1*02301
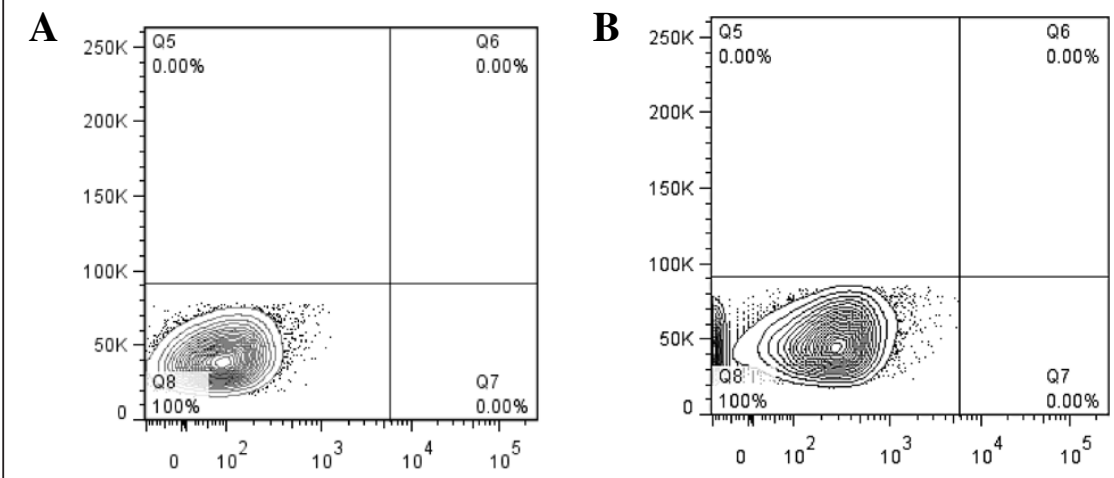

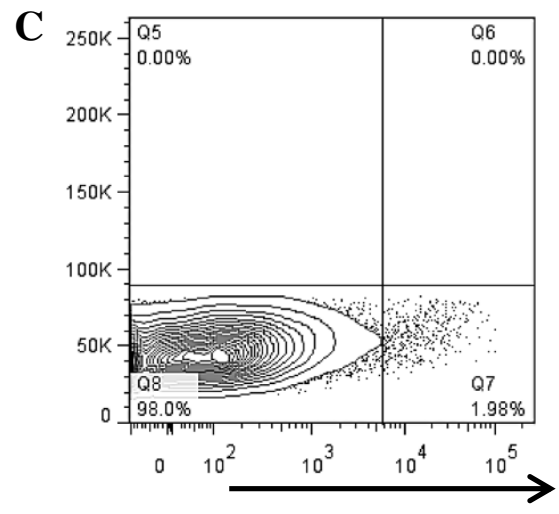

Tetramer (PE) +

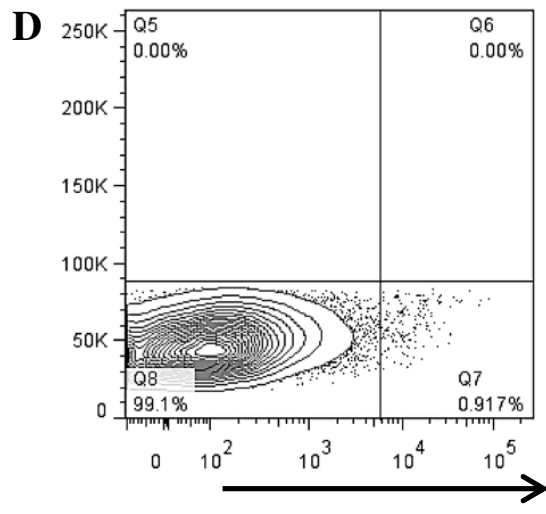

Tetramer (PE) +

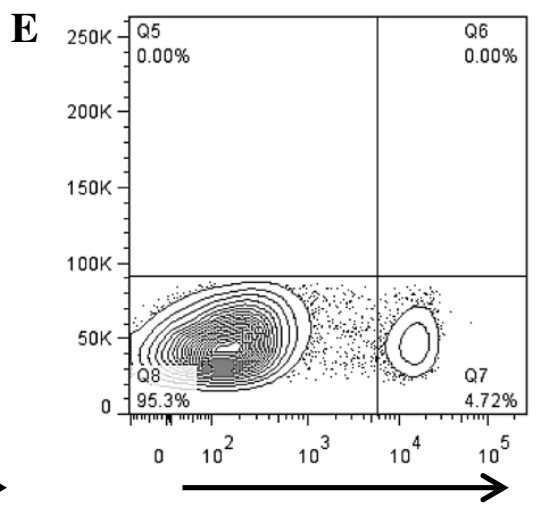

Tetramer (PE) +

Figure 1 Tp1 214-224-BoLA-6*01301 p-MHC class I tetramer staining of bovine CTL line BB007. The CTL line was stained with buffer alone (panel A), p-MHC class I tetramers made with the control peptide, YMYRWWSPL (panel B), p-MHC class I tetramers made with the peptide Tp2 $96-104$, which is restricted by another BoLA molecule [BoLA-T2C] (panel C), p-MHC class I tetramers made in the absence of peptide (panel D) and $\mathrm{p}-\mathrm{MHC}$ class I tetramers made with peptide $\mathrm{Tp1}_{214-224}$ (panel E). All tetramers were generated with PE-streptavidin. 


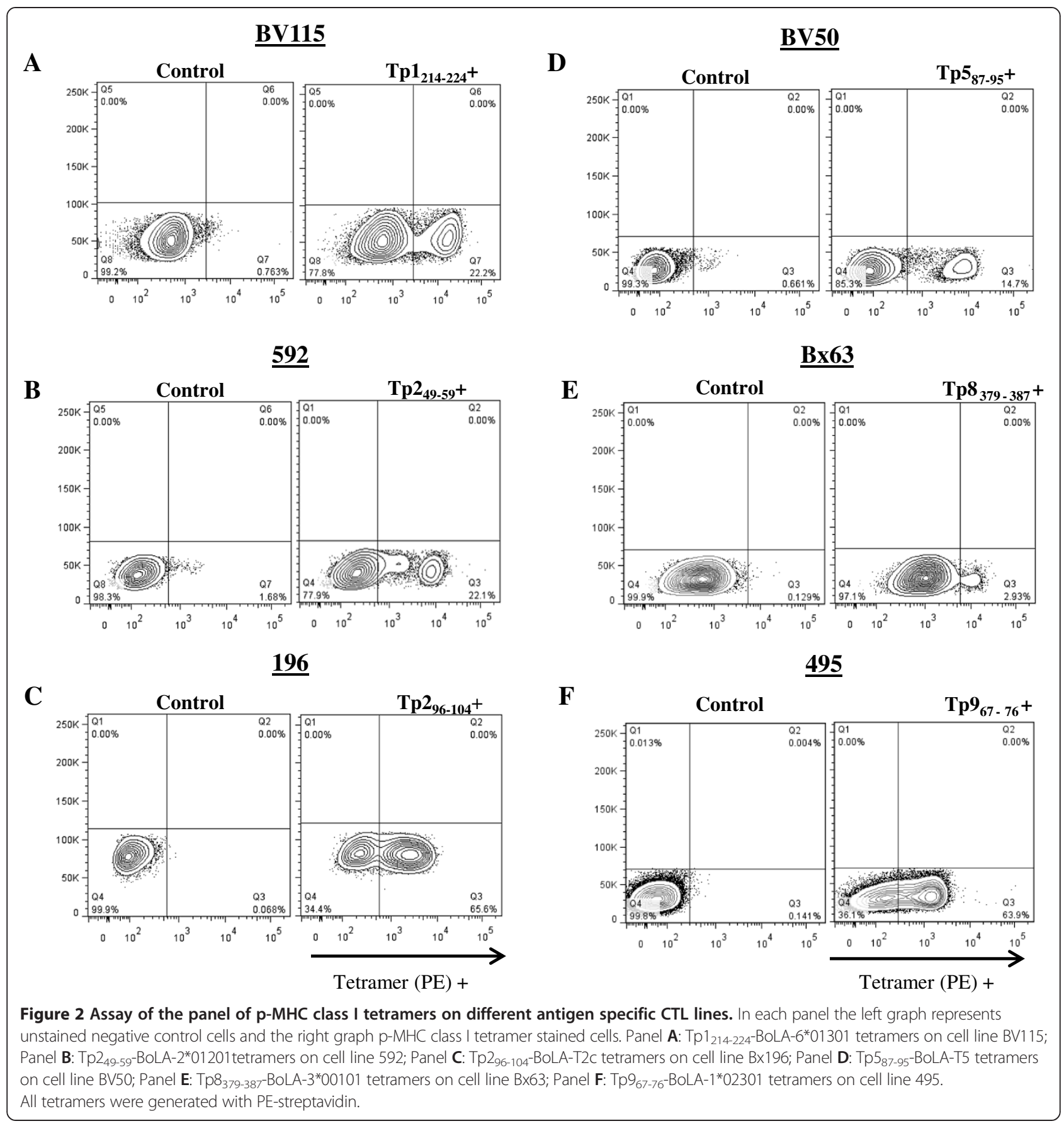

were controlled using an irrelevant CTL line to verify that no nonspecific staining was occurring (data not shown) since no control peptides for these BoLA molecules were available. Tp2 27-37-BoLA-6*04101 p-MHC class I tetramers did not bind a discrete population of cells in cell line BW02 and resembled a non-specific staining profile (data not shown). We provide strong evidence below that this is likely due to $\mathrm{Tp} 2_{29-37}$ rather than $\mathrm{Tp} 2_{27-37}$ being the epitope that binds to BoLA-6*04101 (Figure 3).

\section{A role for NetMHCpan in T. parva CTL epitope identification}

We have previously reported that the NetMHCpan algorithm [45] predicted an alternative epitope sequence for six of the 12 epitopes [30]. Since that time NetMHCpan has been improved and version 2.8 predicts alternative epitopes for only 4 of the 12 epitopes: $\mathrm{Tp}_{207-214}$ instead of $\mathrm{Tp} 7_{206-214}, \mathrm{Tp} 2_{41-48}$ instead of $\mathrm{Tp} 2_{40-48}, \mathrm{Tp} 2_{138-146}$ instead of $\mathrm{Tp} 2_{138-147}$ and $\mathrm{Tp} 2_{29-37}$ instead of $\mathrm{Tp} 2_{27-37}$. As a 


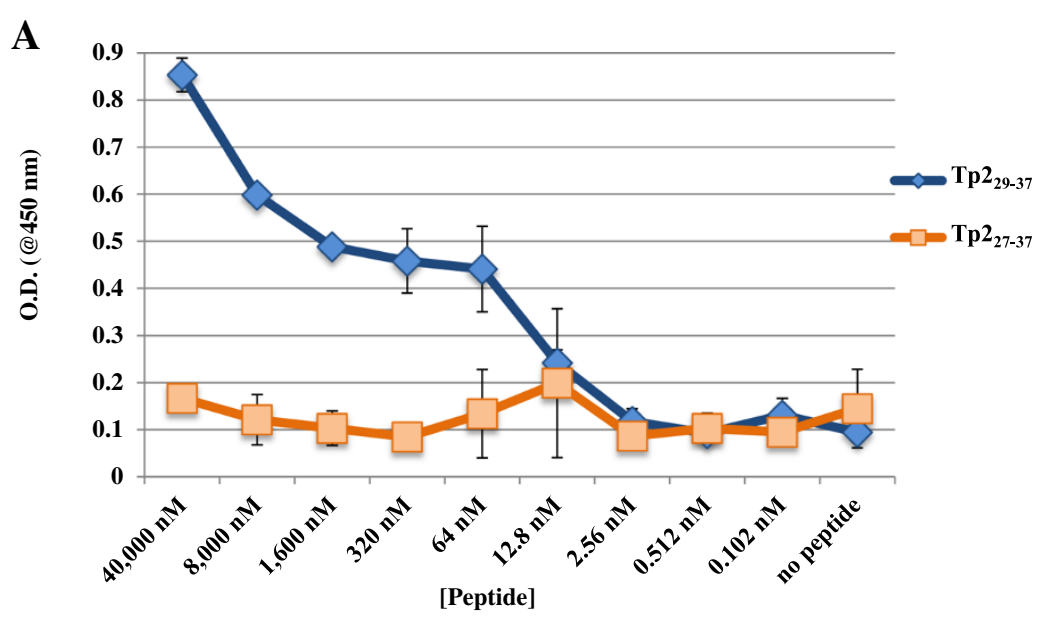

B

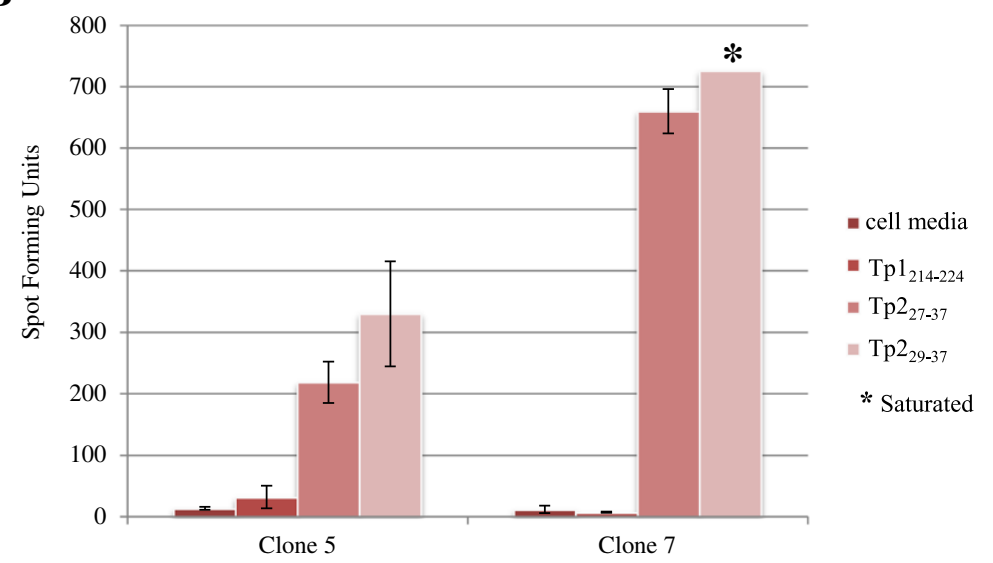

C

BoLA-6*04101

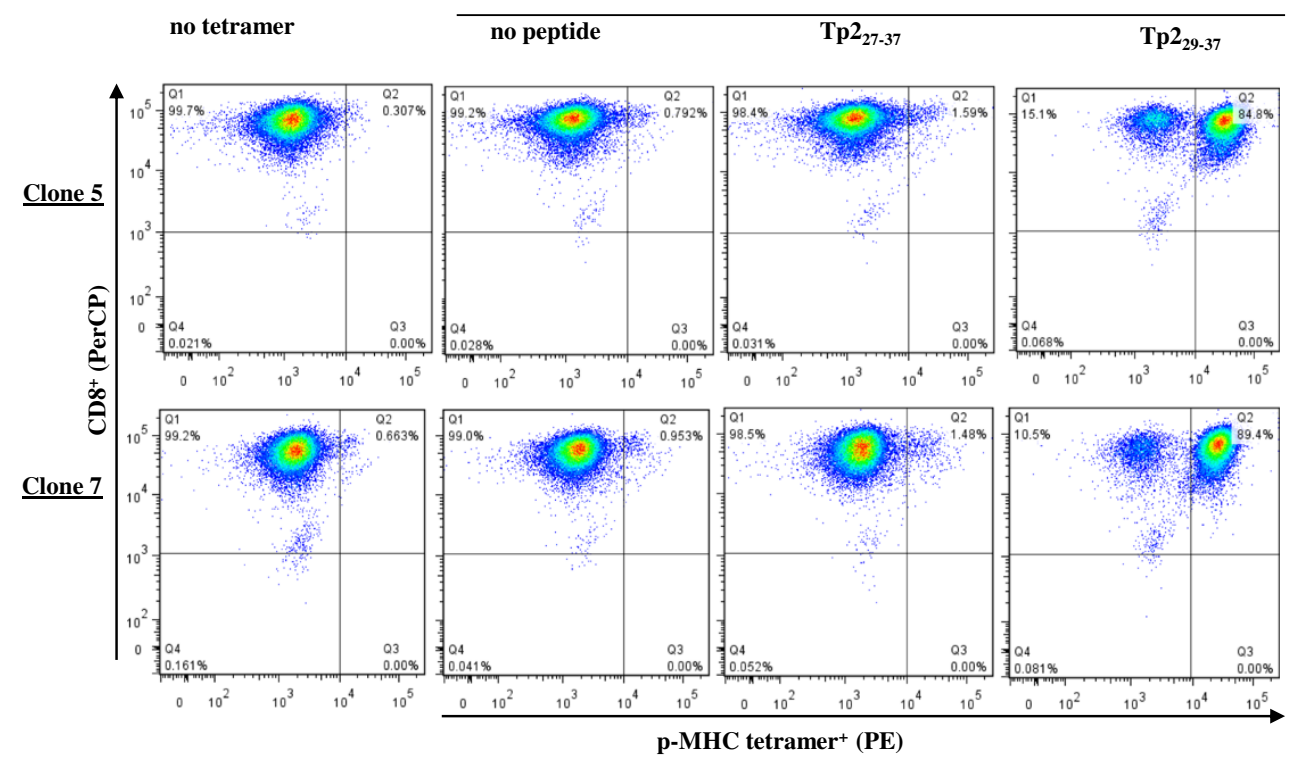

Figure $\mathbf{3}$ (See legend on next page.) 
(See figure on previous page.)

Figure 3 Definition of an alternative Tp2 epitope that binds to BoLA-6*04101. Panel A: p-MHC class I monomer formation ELISA assay using Tp2 $27-37$ and Tp2 29-37 peptides. Panel B: ELISpot performed on two clones (5 and 7) of the cell line BW02 with cell media alone, Tp1 214-224, Tp2 2737 or Tp2 $29-37$ peptides. Data are presented as spot forming units (SFU) and each well contained $2.5 \times 10^{4}$ CTLs. Asterisk (*) indicates saturated wells. Panel C: Two clones of the cell line BW02 was stained with anti-bovine CD8 (PerCP) and different BoLA-6*04101 tetramers. The unstained control or stained with the unfolded (no peptide) BoLA- $6^{*} 04101$ tetramer are depicted on the left. Tetramer labelling was measured on the CD8gated cell population.

measure of predictive accuracy, we use the false positive fraction score. For a given CTL epitope, this score is defined as the number of 8 -11mer peptides with a predicted binding affinity stronger than the epitope divided with the total number of 8-11mer peptides found within the source protein sequence. A false positive fraction score closer to 0 is indicative of a high predictive performance.

NetMHCpan predicted that Tp2 29-37 (EELKKLGML) has a false positive fraction score of zero for BoLA-6*04101 while that for the peptide Tp2 27-37 (SHEELKKLGML) we have been working with (Table 1) was 0.039 (this value has changed from previous predictions with older version of NetMHCpan but is still indicative of a low binding affinity [30]). To experimentally verify this prediction we developed a semi-quantitative ELISA assay as described in [35] to measure p-MHC class I monomer formation (see Materials and Methods). The W6/32 monoclonal antibody used in the ELISA assay binds to $\beta 2 \mathrm{~m}$ from different species but only when $\beta 2 \mathrm{~m}$ is in a complex with $\mathrm{HC}$ and peptide. If a stable p-MHC class I complex is not formed, for example in the absence of peptides, $\beta 2 \mathrm{~m}$ remains free in solution and will not bind to the streptavidin-bound $\mathrm{HC}$ on the plate. Figure $3 \mathrm{~A}$ clearly demonstrates that $\mathrm{Tp} 2_{27-37}$ does not bind to BoLA-6*04101, whereas Tp2 29-37 demonstrates a good binding curve.

We then generated p-MHC class I tetramers made with each one of the two Tp2 sequences to stain BW02 CTL line clones that in ELISpot assay respond to both peptide sequences (Figure 3B). Figure $3 \mathrm{C}$ shows a clear difference in staining profile between the $\mathrm{p}-\mathrm{MHC}$ class I tetramer generated with $\mathrm{Tp} 2_{29-37}$ and the p-MHC class I tetramer generated with $\mathrm{Tp} 2_{27-37}$, with the latter showing a profile similar to that seen for non-specific staining of cells. Thus, our results strongly support the NetMHCpan prediction that $\mathrm{Tp} 2_{29-37}$ and not $\mathrm{Tp} 2_{27-37}$ is the correct epitope sequence for BoLA-6*04101.

Tp1-tetramer positive CTL are also positive for CD8, FasL, and perforin

It has been shown that active CTL express both perforin and Fas-ligand $[1,46,47]$. In order to determine if the cells identified with the tetramers were of the CD8 lineage and expressed cytotoxicity markers, we performed multiple staining of cells. For example, all Tp1 positive cells in the cell line BB007 were CD8-positive (Figure 4A), FasLpositive (Figure 4B) or perforin-positive (Figure 4C). A triple staining confirmed that tetramer-positive cells are also positive for CD8 and perforin (Figure 4D). For the 592, Bx63 and BV50 CTL cell lines analysed, all tetramer positive cells were also positive for CD8 but other markers were not tested (data not shown). We have demonstrated a correlation between the presence of perforin in tetramerpositive cells and specific cytotoxic activity in BV115 and BB007 cell lines as well as from cells isolated ex vivo (data not shown, manuscript in preparation).

Ex vivo analysis of CTL following ITM vaccination of cattle With the validation of $\mathrm{p}-\mathrm{MHC}$ class I tetramers, we wanted to determine if we could detect antigen specific CTL directly isolated from cattle. Three BoLA-A18 positive animals that were predicted to mount a CTL response to antigen Tp1 were vaccinated by the ITM method [reviewed in [24]] using T. parva strain Muguga 3308. Appearance of Tp1 specific CTL in peripheral blood was monitored every two days following infection using $\mathrm{Tp} 1_{214-224}$-BoLA-6*01301 tetramers (Figure 5). As illustrated, Tp1 positive cells were successfully identified on days 15 to 17 at a frequency of about $1 \%$ of PBMC. The appearance of tetramer-positive cells correlated with previous reports of cytotoxic activity towards T. parva peaking at day 18 post-infection [48-50].

\section{Predicted peptide binding specificity as a means of clustering of the seven BoLA MHC class I molecules}

We used the MHCcluster 2.0 server [51] to determine the functional relationship of the different BoLA class I molecules based on their predicted peptide binding specificities. According to this analysis BoLA-T5 and BoLA-1*02301 cluster together as depicted in the dendrogram (Figure 6A). Their similarity in function is more apparent in the sequence logo of the amino acid motifs predicted to bind the two BoLA molecules (Figure 6A) and the heat-map representation of the degree of functional relationship between the different BoLA molecules (Figure 6B).

The algorithms predicted that the CTL epitope from Tp5 $\left[{ }^{87}\right.$ SKADVIAKY $\left.{ }_{95}\right]$, which was found to be restricted by BoLA-T5 (Table 1) should also bind BoLA-1*02301 (Figure 7A). This was confirmed by $\mathrm{p}-\mathrm{MHC}$ monomer binding assays (data not shown). We then generated

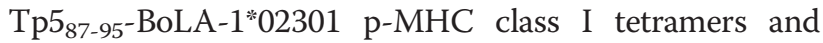
stained BV50 and 495 CTL lines, which are restricted by BoLA-T5 and BoLA-1*02301, respectively (Table 1). The only CTL line stained by this tetramer was BV50, which is 


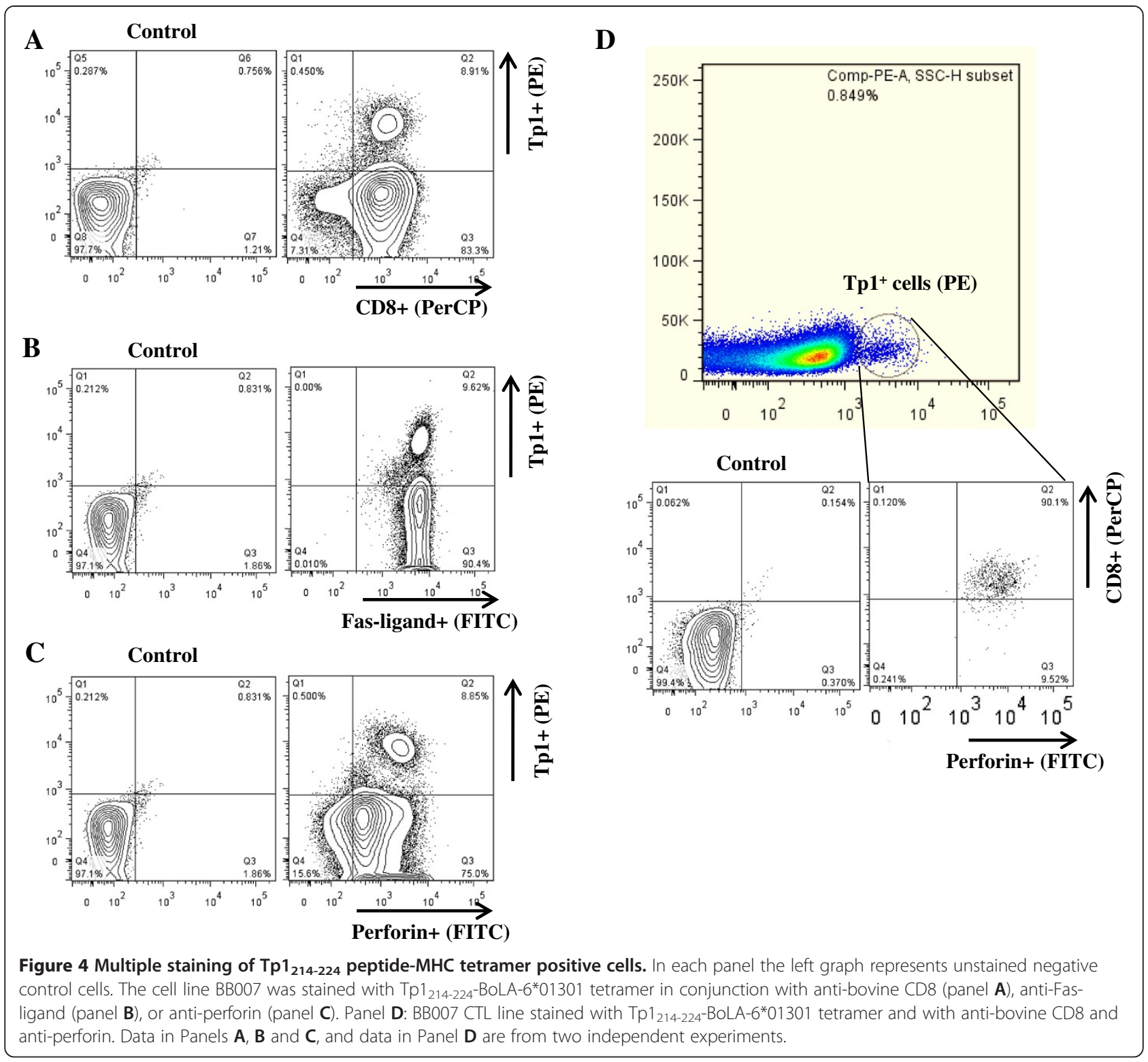

also stained by $\mathrm{Tp} 5_{87-95}$-BoLA-T5 $\mathrm{p}$-MHC class I tetramers (Figure $7 \mathrm{~B}$ ). Interestingly, both tetramers bind the same population of CTL as demonstrated by co-staining of the BV50 cell line with p-MHC class I tetramers using Tp5 $5_{87-95}$-BoLA-1*02301 labelled with PE and Tp5 ${ }_{87-95^{-}}$ BoLA-T5 labelled with APC. (Figure 7C). A MUSCLE alignment of the BoLA class I molecules revealed that there are only 15 amino acid differences between BoLA1*02301 and BoLA-T5 (highlighted in Figure 8A by the amino acid letters in red). The close sequence identity between these two BoLA class I molecules may explain their similar peptide binding specificity (Figure 8A). However, three of the 15 amino acid polymorphisms map to the peptide binding groove in the $\alpha 2$ domain (Figure 8B). Nevertheless, our results establish that the
Tp5 $57-95$ epitope can be presented not only by BoLA-T5 but by BoLA-1*02301 as well.

\section{Discussion}

Peptide-MHC class I tetramer complexes have become essential tools in cellular immunology to decipher and characterize epitope-specific $\mathrm{CD}^{+} \mathrm{T}$ cell immune responses $[12,13,21]$. They are especially useful for detection of CTL that occur at low frequency and are finding many applications in ex vivo assays for direct assessment of $\mathrm{T}$ cell responses. Such reagents have become indispensable tools in murine and human immunology but are generally lacking for many important livestock species. In an effort to provide reagents to fill this gap, 
Day 8 p.i.

Animal 1
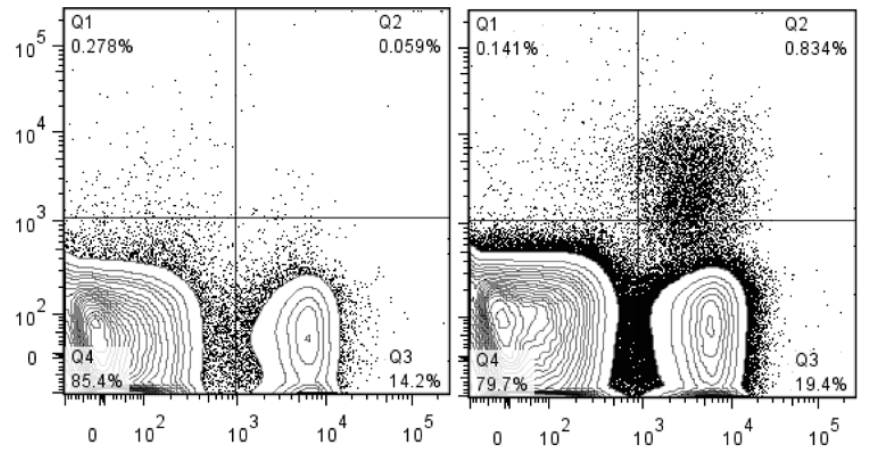

Day 8 p.i.

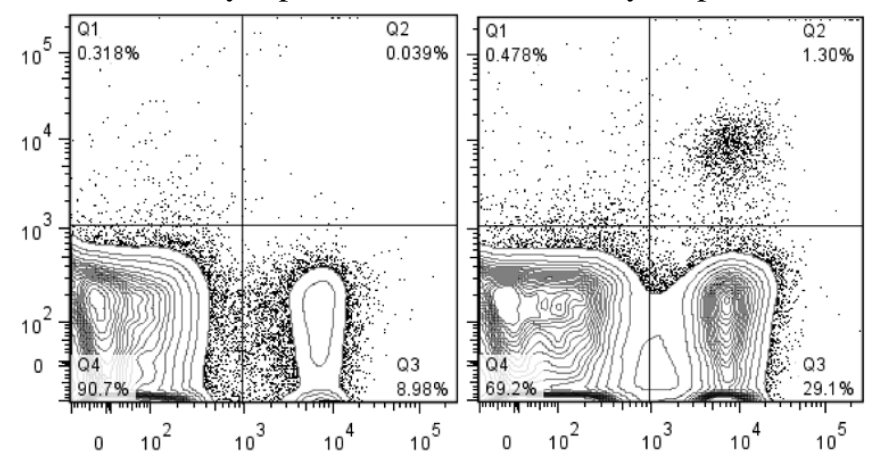

Day 8 p.i.

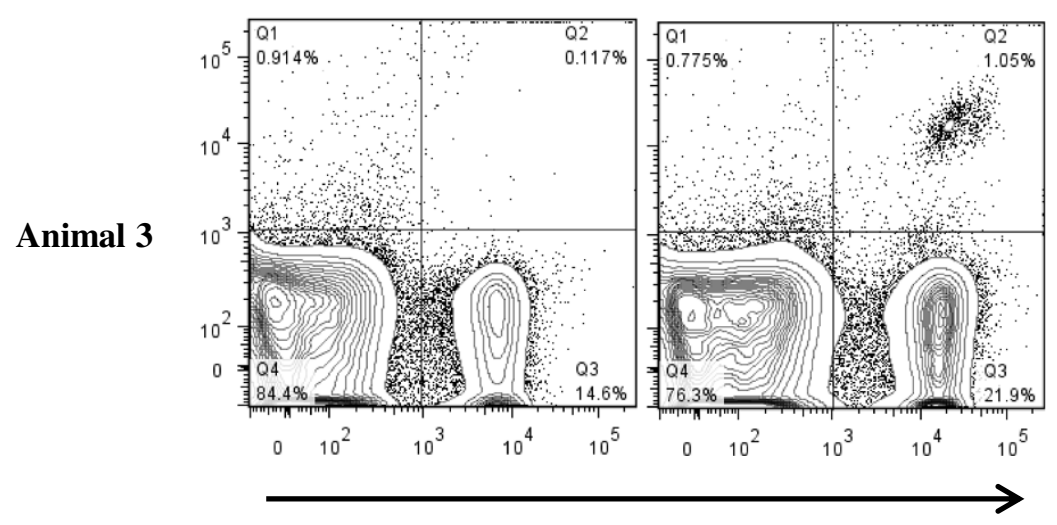

\section{CD8+ (PerCP)}

Figure 5 Identification of $\mathrm{Tp}_{214-224}$ peptide-MHC tetramer positive cells in ex vivo assays. PBMC were isolated from three BoLA-A18 cattle vaccinated with the live T. parva (Muguga 3308 strain) and stained with Tp1 214-224-BoLA-6*01301 tetramers at day 8 and day 15-17 post infection (pi). Tetramer labelling was measured on the CD8-gated population.

we recently described initial efforts to develop p-MHC class I tetramers for use in swine and bovine research $[30,34]$ using a simple in-house system that permits generation of $\mathrm{p}-\mathrm{MHC}$ class I tetramers with a turnaround time of $48 \mathrm{~h}$ [11]. Here, we report on p-MHC class I tetramers made from seven BoLA MHC class I genes and the power of integrating the on demand tetramer system with CTL epitope prediction data from NetMHCpan, a pan specific algorithm, and MHCcluster, a method for clustering of MHC molecules based on function, i.e., their predicted peptide binding specificities, rather than sequence. 


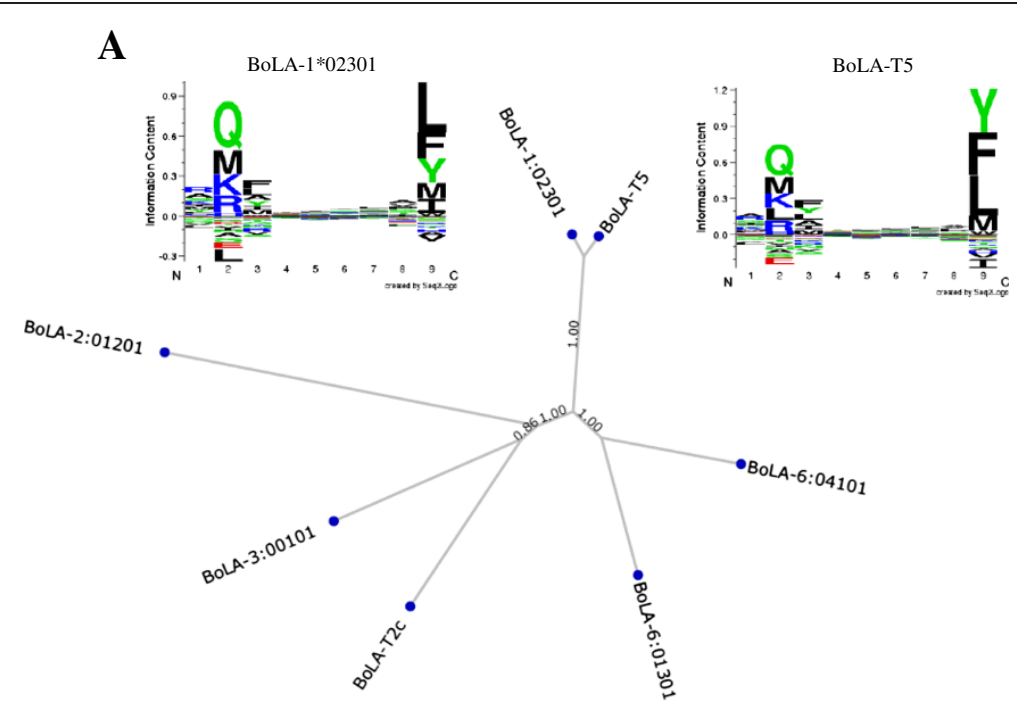

B

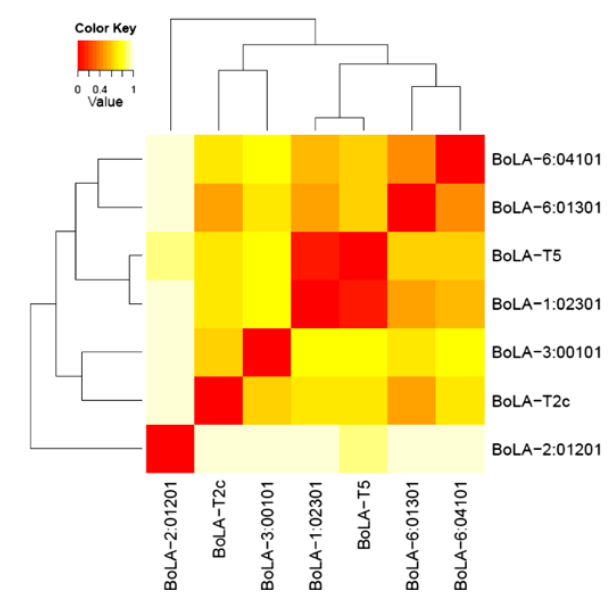

Figure 6 MHCcluster prediction of the functional similarity of BoLA-T5 and BoLA-1*02301. Panel A: UPGMA tree-based clustering of the relationship between the seven BoLA molecules (sequence logo representations of the predicted binding motifs of BoLA-T5 and BoLA-1*02301 were generated by MHCcluster using Seq2Logo [52]); Panel B; heat-map visualization of the degree of functional relationship between the seven BoLA molecules, red colour shows closer functional relationship.

We used the novel immunological reagents we generated to facilitate our research on ECF, a lethal disease of cattle. Parasite-specific CTL induced by the ITM vaccine play a major role in mediating immunity to ECF [25,28,29]. A number of T. parva antigens that are the targets of CTL induced by ITM have been identified using high-throughput IFN- $\gamma$ ELISpot immunoscreens of antigen presenting cells transfected with either candidate T. parva genes or pools of parasite cDNA libraries [29]. Positive genes were then tested in cytolytic assays and CTL epitopes mapped by use of synthetic overlapping peptides. Based on such data a panel of 12 experimentally verified epitope sequences derived from seven $T$. parva antigens and restricted by ten BoLA class I molecules have been reported [ 29 and unpublished data]. However, these peptide sequences were not subjected to systematic analyses to determine minimal epitope sequence data and due to a lack of appropriate reagents the epitopes were not verified in independent assays, e.g., in peptide-BoLA binding assays. The prediction of alternative sequences for some of the CTL epitopes by NetMHCpan [30] has raised questions regarding the performance of the algorithm as well as the veracity of CTL epitope sequences. We have addressed some of these issues.

The method of Leisner et al. works well for production of seven recombinant BoLA MHC class I molecules, adding to the list of mammalian MHC molecules generated by this system. We have made and validated the use of $\mathrm{p}-$ MHC class I tetramers that allow us to rapidly identify $T$. parva specific CTL responses directed to one of seven epitopes on five different antigens (Figures 1, 2, and 3). We used these reagents to demonstrate that all Tp1-specific CTL co-express CD8, FasL or perforin (Figure 4). Such assays facilitate rapid typing of the predicted functionality of 


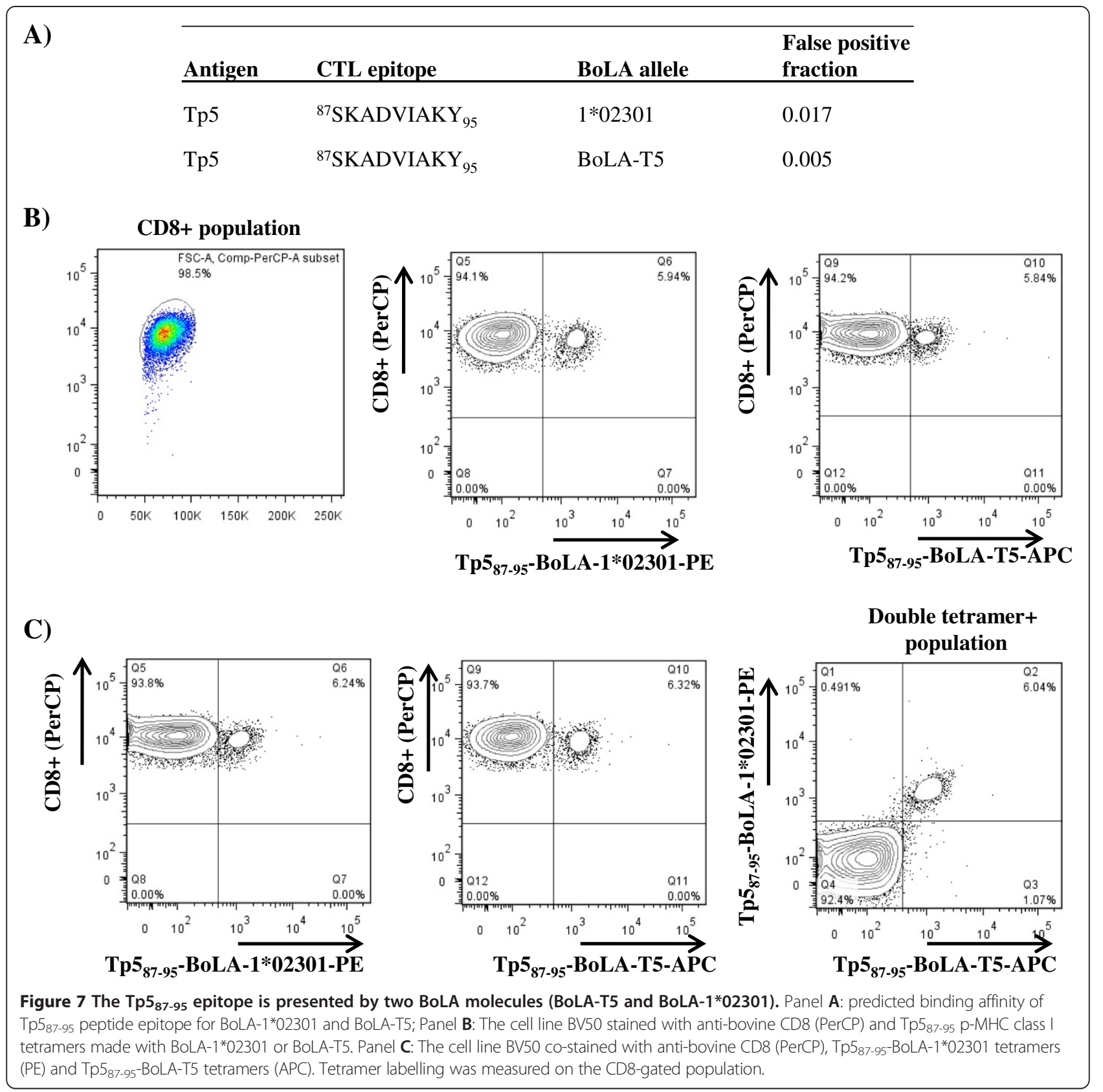

T. parva specific CTL. This is important for subunit vaccine development studies since in the past we have demonstrated priming of peptide specific IFN $-\gamma$ ELISpot $\mathrm{CD}^{+} \mathrm{T}$ cell responses in the absence of cytolytic activity [28], and only the latter activity correlates with immunity to ECF. The ability to detect cytolytic activity in peripheral blood post-vaccination is the range of 14 to 21 days [48-50]. However, several rounds of CTL in vitro stimulation are required for detection of cytolytic activity. Using the Tp1specific tetramer we were able to detect CTL in BoLAA18 cattle as early as day 13 post-vaccination by the live parasite based ITM vaccine (data not shown). The CTL response peaked at about day 15 (Figure 5). Thus, the Tp1-specific tetramers demonstrate high sensitivity and great potential as diagnostic tools for detecting ECF immunity in cattle with the ability to stain cells isolated ex vivo from infected animals without further stimulation and expansion in vitro. While the remaining $\mathrm{p}-\mathrm{MHC}$ class I tetramers remain to be validated in ex vivo assays, we expect that our collection of p-MHC class I tetramers will permit studies on the kinetics and functionality of antigen specific CTL responses to T. parva during infection and facilitate immunogenicity studies during subunit vaccine trials. Moreover, as new CTL epitopes restricted by these 


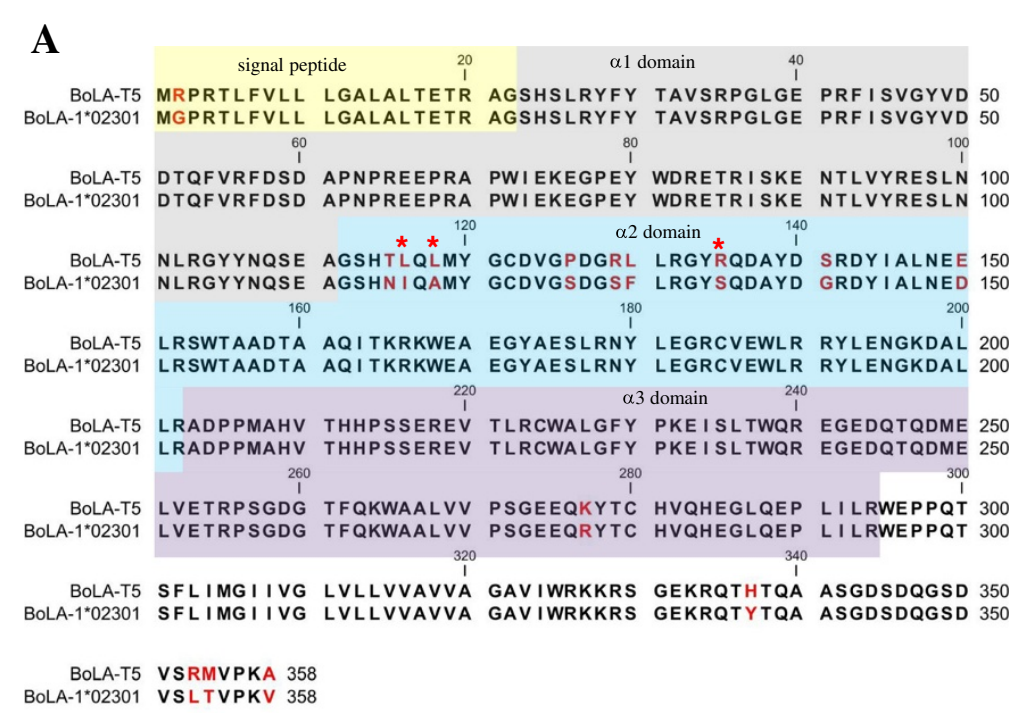

B
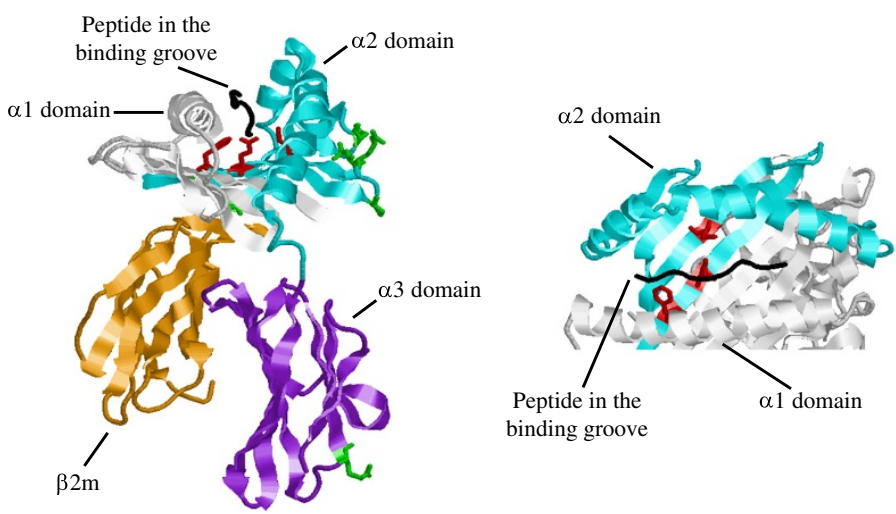

Figure 8 Sequence alignment of BoLA-T5 and BoLA-1*02301 molecules and identification of amino acid differences in the peptidebinding groove. Panel A: MUSCLE alignment of BoLA-T5 and BoLA-1*02301 amino acid sequence; differences in amino acid sequence is highlighted by the red letters; asterisks $\left(^{*}\right)$ in red indicate amino acids that map to the pseudo-sequence of 34 amino acids that were defined as in contact with peptide; sequence highlighted in yellow indicate the signal peptide; sequence highlighted in grey indicate the a1 domain; sequence highlighted in blue indicate the a2 domain; sequence highlighted in purple indicate the a3 domain. Panel B: Ribbon drawing of the BoLA-2*01801 [43] molecule with position of all amino acid differences in the a2 (highlighted in blue) and a3 (highlighted in purple) domains between BoLA-T5 and BoLA-1*02301. Amino acids that map to the pseudo-sequence are illustrated in red; amino acids that do not map to the pseudo-sequence are illustrated in green. The $\beta 2 \mathrm{~m}$ molecule is illustrated in orange and the peptide in black.

BoLA molecules are identified, in future studies we will be able to rapidly expand the repertoire of $\mathrm{p}-\mathrm{MHC}$ class I tetramers available for ECF research.

Several unexpected results were predicted through the use of NetMHCpan and MHCcluster. The first is that NetMHCpan predicted that $\mathrm{Tp} 2_{29-37}$ rather than $\mathrm{Tp} 2_{27-37}$ is likely to be the correct peptide sequence that binds to BoLA-6*04101 (Figure 3). The longer Tp2 peptide sequence works in both ELISpot and cytolytic assays (our data and [29]) but this peptide does not bind to BoLA$6 * 04101$ (Figure 3). We presume that the peptide is processed to the functional epitope during the ELISpot assays, which does not occur during the peptide MHC binding assays or formation of $\mathrm{p}-\mathrm{MHC}$ class I tetramers.
NetMHCpan also predicted three alternative epitopes from those we have previously described: $\mathrm{Tp} 7_{207-214}$ instead of $\mathrm{Tp} 7_{206-214}, \mathrm{Tp} 2_{41-48}$ instead of $\mathrm{Tp} 2_{40-48}$, and Tp2 138-146 instead of Tp2 138-147. Due to a lack of CTL lines of appropriate specificity, we have not been able to test these predictions. However, $\mathrm{Tp} 7_{207-214}$ has been previously shown to be negative in ELISpot assays [29]. Preliminary data from our group (not shown) has determined a higher binding affinity of $\mathrm{Tp} 7_{207-214}$ for BoLA-T7 (Kd value of $142 \mathrm{nM}$ ) compared to the binding affinity of $\mathrm{Tp}_{206-214}$ (Kd value of $252 \mathrm{nM}$ ). This discrepancy and the alternative epitopes predicted for Tp2 remains to be resolved.

One of the outputs of the MHCcluster server is a treebased (Figure 6A) and heat-map (Figure 6B) visualization 
of the functional relationship between $\mathrm{MHC}$ molecules based on their predicted peptide binding specificity rather than sequence alignment of the MHC molecules themselves. For example, it is known that HLA-A*0201 and HLA A*0301 share 93\% sequence identity but exhibit completely different peptide binding specificities [19]. Thus, clustering on function rather than sequence of MHC molecules is a more important parameter in CTL biology and immunology. NetMHCpan predicted that the epitope Tp5 $5_{87-95}$ should bind to BoLA-1*02301 (with a false positive fraction of 0.017 ) in addition to BoLA-T5, the original molecule that was defined to present the $\mathrm{Tp} 5_{87-95}$ epitope by parasite infected cells (Table 1). Using both peptideBoLA binding assays and $\mathrm{p}-\mathrm{MHC}$ class I tetramers we demonstrate that the $\mathrm{Tp} 5_{87-95}$ epitope does indeed bind both BoLA molecules and that a single TCR can recognize the $\mathrm{Tp} 5_{87-95}$ epitope presented by either BoLA molecule (Figure 7). This suggests that as for HLA molecules, it will be possible to categorize BoLA molecules into supertypes based on function. More importantly the functional overlap of BoLA molecules suggest that it should be possible to select a repertoire of $T$. parva antigens to cover a broader population of cattle than indicted by the limited specificity of CTL responses generated by the live ITM vaccine.

The finding that the $\mathrm{Tp} 5_{87-95}$ epitope binds to two BoLA molecules was unexpected. What is more surprising was the observation that three of 15 amino acid sequence polymorphisms between the BoLA molecules map to the peptide binding groove (Figure 8B). More specifically they map to the pseudo-sequence of 34 amino acids in HLA molecules, which form the basis of the pan prediction capacity of NetMHCpan [37]. These 34 polymorphic residues have been defined from crystal structure studies as being within 4.0 Angstrom $(\AA)$ of the peptide in any of a representative set of HLA-A and HLA-B structures binding a nonameric peptide [37] and hence are predicted to play a critical role in peptide binding. Leucine in BoLA-T5 is replaced by isoleucine in BoLA-1*02301 at position 94; leucine by alanine at position 96 and arginine by serine at position 113 in the mature protein (highlighted with red asterisk in Figure 8A). Of these substitutions two are conservative in nature. Our data indicates that these changes and the non-conservative amino acid substitution do not have a dramatic influence on the specificity of peptide binding. The NetMHCpan method has, in several benchmark studies, proven to accurately predict the peptide binding motif for molecules characterised by limited or no experimental peptide binding data [16,53,54]. In addition, NetMHCpan can differentiate between critical and less critical amino acid substitutions in the MHC pseudosequence in situations where the amino acid variations have been observed and used in training the method [39]. As the training data for NetMHCpan increases it should become possible to predict such subtleties in peptide binding to MHC molecules.

An essential feature of the system we have described is that $\mathrm{p}-\mathrm{MHC}$ class I tetramers are generated over a $48 \mathrm{~h}$ time frame using an easy protocol starting from the raw ingredients of recombinant MHC class I HC, synthetic peptide and recombinant $\beta 2 \mathrm{~m}$. We have also used the BoLA molecules to develop a simple ELISA based method to determine peptide-MHC complex formation. The power of combining such experimental verifications with predictions from NetMHCpan is highlighted by our results and have important implications for research on infectious diseases affecting not only cattle but other animal species including humans. We have continued to improve NetMHCpan using peptide-BoLA binding data (manuscript in preparation) and expect similar improvements to occur through incorporation of data from other $\mathrm{MHC}$ projects. These new bovine MHC class I tetramers are sensitive tools that can be used to study the immune responses in cattle e.g. the $\mathrm{CD}^{+} \mathrm{T}$ cells that play a role in Theileria parva immune responses or in other parasitic or viral diseases where CTL contribute to immunity [43,55]. More BoLA class I alleles could be included in the pipeline as more information about MHC class I expression in cattle of eastern, central and southern Africa is generated.

\section{Abbreviations \\ Å: Angstrom; AP: Alkaline phosphatase; APC: Allophycocyanin; $32 \mathrm{~m}$ : Beta-2- microglobulin; BoLA: Bovine leukocyte antigen; BREAD: Basic research to enable agricultural development; BSA: Bovine serum albumin; CTL: Cytotoxic T lymphocytes; E. coli: Escherichia coli; ECF: East Coast fever; \\ EDTA: Ethylenediaminetetraacetic acid; ELISA: Enzyme linked immunosorbent assay; ER: Endoplasmic reticulum; FBS: Fetal bovine serum; FITC: Fluorescein isothiocyanate; HC: Heavy chain; IFN: Interferon; IgG: Immunoglobulin-G; IL: Interleukin; IPTG: Isopropyl $\beta$-D-1-thiogalactopyranoside; ITM: Infection and treatment method; MHC: Major histocompatibility complex; NSF: National Science foundation; O.D.: Optical density; PBMC: Peripheral blood mononuclear cells; PBS: Phosphate buffered saline; PE: Phycorerythrin; PerCP: Peridinin chlorophyll protein; pi: post-infection; PLC: Peptide-loading-complex; PMSF: Phenylmethylsulfonyl fluoride; T. parva: Theileria parva; TCGF: T-cell growth factor; TCR: T-cell receptor; TLCK: Tosyllysine chloromethylketone; TPCK: Tosyl phenylalanyl chloromethyl ketone; TpM: T. parva Muguga transformed lymphocytes; UF: Unfolded.}

\section{Competing interests}

The authors declare that they have no competing interests.

\section{Authors' contributions}

NS and VN conceived the experiments and wrote the manuscript. NS typed the animals; prepared the tetramers; performed flow cytometry, ELISpot and binding assays; and analysed the data. AMH carried out Tp2 27-37/BoLA6*04101 and Tp5/BoLA-1*02301 binding assays. LS planned and supervised the animal experiment. RS and EA prepared/stimulated the CTL lines in vitro and performed ELISpot assays. MN developed NetMHCpan and performed predictions of peptide binding on the BoLA class I molecules. SB expressed the recombinant BoLA class I molecules and developed the "on-demand" generation of MHC-tetramer technology. All authors read and approved the final manuscript.

\section{Acknowledgements}

Particular thanks go to John Wasilwa for technical assistance with the flow cytometer. Thanks also go to FlowJo for the free licence to run the flow cytometry analysis software given to scientists in Africa. This research was 
funded through an award (No. 0965346) from the BREAD program of the National Science Foundation (USA); through the CGIAR Research Program on Livestock and Fish; and through the Norman Borlaug Commemorative Research Initiative, an initiative between the Feed the Future program of USAID and USDA-ARS (58-5348-2-117F).

\section{Author details}

'International Livestock Research Institute (ILRI), P.O. Box 30709, Nairobi 00100, Kenya. ${ }^{2}$ Department of International Health, Immunology and Microbiology, University of Copenhagen, Copenhagen, Denmark. ${ }^{3}$ Center for Biological Sequence Analysis, Danish Technical University, Copenhagen, Denmark. ${ }^{4}$ Universidad Nacional de San Martín, San Martín, Buenos Aires, Argentina.

Received: 15 October 2013 Accepted: 7 April 2014 Published: 28 April 2014

\section{References}

1. Chavez-Galan L, Arenas-Del Angel MC, Zenteno E, Chavez R, Lascurain R: Cell death mechanisms induced by cytotoxic lymphocytes. Cell Mol Immunol 2009, 6:15-25.

2. Rudolph MG, Stanfield RL, Wilson IA: How TCRs bind MHCs, peptides, and coreceptors. Annu Rev Immunol 2006, 24:419-466.

3. Apostolopoulos V, Lazoura E, Yu M: MHC and MHC-like molecules: structura perspectives on the design of molecular vaccines. Adv Exp Med Biol 2008, 640:252-267.

4. Pamer $E_{1}$ Cresswell P: Mechanisms of MHC class I-restricted antigen processing. Annu Rev Immunol 1998, 16:323-358.

5. Donaldson JG, Williams DB: Intracellular assembly and trafficking of MHC class I molecules. Traffic 2009, 10:1745-1752.

6. Kisselev AF, Akopian TN, Woo KM, Goldberg AL: The sizes of peptides generated from protein by mammalian 26 and $20 \mathrm{~S}$ proteasomes. Implications for understanding the degradative mechanism and antigen presentation. J Biol Chem 1999, 274:3363-3371.

7. Serwold T, Gonzalez F, Kim J, Jacob R, Shastri N: ERAAP customizes peptides for MHC class I molecules in the endoplasmic reticulum. Nature 2002, 419:480-483.

8. Ortmann B, Copeman J, Lehner PJ, Sadasivan B, Herberg JA, Grandea AG Riddell SR, Tampe R, Spies T, Trowsdale J, Cresswell P: A critical role for tapasin in the assembly and function of multimeric MHC class I-TAP complexes. Science 1997, 277:1306-1309.

9. Whelan JA, Dunbar PR, Price DA, Purbhoo MA, Lechner F, Ogg GS, Griffiths G, Phillips RE, Cerundolo V, Sewell AK: Specificity of CTL interactions with peptide-MHC class I tetrameric complexes is temperature dependent J Immunol 1999, 163:4342-4348

10. Wooldridge L, Lissina A, Cole DK, van den Berg HA, Price DA, Sewell AK Tricks with tetramers: how to get the most from multimeric peptideMHC. Immunology 2009, 126:147-164.

11. Leisner C, Loeth N, Lamberth K, Justesen S, Sylvester-Hvid C, Schmidt EG Claesson M, Buus S, Stryhn A: One-pot, mix-and-read peptide-MHC tetramers. PLoS One 2008, 3:e1678.

12. Sims S, Willberg C, Klenerman P: MHC-peptide tetramers for the analysis of antigen-specific T cells. Expert Rev Vaccine 2010, 9:765-774.

13. Xu XN, Screaton GR: MHC/peptide tetramer-based studies of T cell function. J Immunol Methods 2002, 268:21-28.

14. Deres K, Beck W, Faath S, Jung G, Rammensee HG: MHC/peptide binding studies indicate hierarchy of anchor residues. Cell Immunol 1993, 151:158-167.

15. Neefjes J, Jongsma ML, Paul P, Bakke O: Towards a systems understanding of MHC class I and MHC class II antigen presentation. Nat Rev Immunol 2011, 11:823-836.

16. Karosiene E, Lundegaard C, Lund O, Nielsen M: NetMHCcons: a consensus method for the major histocompatibility complex class I predictions. Immunogenetics 2012, 64:177-186.

17. Nielsen $M$, Lundegaard $C$, Blicher $T$, Lamberth $K$, Harndahl $M$, Justesen $S$, Roder G, Peters B, Sette A, Lund O, Buus S: NetMHCpan, a method for quantitative predictions of peptide binding to any HLA-A and $-B$ locus protein of known sequence. PLOS One 2007, 2:e796.

18. Nielsen M, Lundegaard C, Worning P, Lauemoller SL, Lamberth K, Buus S, Brunak S, Lund O: Reliable prediction of T-cell epitopes using neural networks with novel sequence representations. Protein Sci 2003, 12:1007-1017.
19. Lundegaard C, Lund O, Buus S, Nielsen M: Major histocompatibility complex class I binding predictions as a tool in epitope discovery. Immunology 2010, 130:309-318.

20. Kurtulus S. Hildeman D: Assessment of CD4(+) and CD8 (+) T cell responses using MHC class I and II tetramers. Methods Mol Biol 2013, 979:71-79.

21. He XH, Xu LH, Liu Y: Procedure for preparing peptide-major histocompatibility complex tetramers for direct quantification of antigen-specific cytotoxic T lymphocytes. World I Gastroenterol 2005, 11:4180-4187.

22. Bishop R, Musoke A, Morzaria S, Gardner M, Nene V: Theileria: intracellular protozoan parasites of wild and domestic ruminants transmitted by ixodid ticks. Parasitology 2004, 129(Suppl):S271-S283

23. Gachohi J, Skilton R, Hansen F, Ngumi P, Kitala P: Epidemiology of east coast fever (Theileria parva infection) in Kenya: past, present and the future. Parasit Vectors 2012, 5:194.

24. Di Giulio G, Lynen G, Morzaria S, Oura C, Bishop R: Live immunization against East Coast fever-current status. Trends Parasitol 2009, 25:85-92.

25. Morrison Wl: Progress towards understanding the immunobiology of Theileria parasites. Parasitology 2009, 136:1415-1426.

26. Global Alliance for Livestock Veterinary Medicines (GALVmed). http://www.galvmed.org/2012/03/east-cost-fever-vaccine-launch-arushatanzania/.

27. MacHugh ND, Connelley T, Graham SP, Pelle R, Formisano P, Taracha EL, Ellis SA McKeever DJ, Burrells A, Morrison Wl: CD8+ T-cell responses to Theileria parva are preferentially directed to a single dominant antigen: Implications for parasite strain-specific immunity. Eur J Immunol 2009, 39:2459-2469.

28. Graham SP, Pelle R, Honda Y, Mwangi DM, Tonukari NJ, Yamage M, Glew EJ, de Villiers EP, Shah T, Bishop R, Abuya E, Awino E, Gachanja J, Luyai AE, Mbwika F, Muthiani AM, Ndegwa DM, Njahira M, Nyanjui JK, Onono FO, Osaso J, Saya RM, Wildmann C, Fraser CM, Maudlin I, Gardner MJ, Morzaria SP, Loosmore S, Gilbert SC, Audonnet JC, et al: Theileria parva candidate vaccine antigens recognized by immune bovine cytotoxic $T$ lymphocytes. Proc Natl Acad Sci USA 2006, 103:3286-3291.

29. Graham SP, Pelle R, Yamage M, Mwangi DM, Honda Y, Mwakubambanya RS, de Villiers EP, Abuya E, Awino E, Gachanja J, Mbwika F, Muthiani AM, Muriuki C, Nyanjui JK, Onono FO, Osaso J, Riitho V, Saya RM, Ellis SA, McKeever DJ, MacHugh ND, Gilbert SC, Audonnet JC, Morrison WI, van der Bruggen $P$, Taracha EL: Characterization of the fine specificity of bovine CD8 T-cell responses to defined antigens from the protozoan parasite Theileria parva. Infect Immun 2008, 76:685-694.

30. Nene V, Svitek N, Toye P, Golde WT, Barlow J, Harndahl M, Buus S, Nielsen M: Designing bovine T cell vaccines via reverse immunology. Ticks Tick Borne Dis 2012, 3:188-192.

31. Ferre H, Ruffet E, Blicher T, Sylvester-Hvid C, Nielsen LL, Hobley TJ, Thomas OR, Buus S: Purification of correctly oxidized MHC class I heavy-chain molecules under denaturing conditions: a novel strategy exploiting disulfide assisted protein folding. Protein Sci 2003, 12:551-559.

32. Bernard A, Payton M: Fermentation and growth of Escherichia coli for optimal protein production. Curr Protoc Protein Sci 2001, Chapter 5:3.

33. Ostergaard Pedersen L, Nissen MH, Hansen NJ, Nielsen LL, Lauenmoller SL, Blicher T, Nansen A, Sylvester-Hvid C, Thromsen AR, Buus S: Efficient assembly of recombinant major histocompatibility complex class I molecules with preformed disulfide bonds. Eur I Immunol 2001, 31:2986-2996.

34. Pedersen LE, Harndahl M, Rasmussen M, Lamberth K, Golde WT, Lund O, Nielsen M, Buus S: Porcine major histocompatibility complex (MHC) class I molecules and analysis of their peptide-binding specificities. Immunogenetics 2011, 63:821-834.

35. Sylvester-Hvid C, Kristensen N, Blicher T, Ferre H, Lauemoller SL, Wolf XA Lamberth K, Nissen MH, Pedersen LO, Buus S: Establishment of a quantitative ELISA capable of determining peptide - MHC class I interaction. Tissue Antigens 2002, 59:251-258.

36. Steinaa L, Saya R, Awino E, Toye P: Cytotoxic T lymphocytes from cattle immunized against Theileria parva exhibit pronounced cross-reactivity among different strain-specific epitopes of the $\mathrm{Tp} 1$ antigen. Vet Immunol Immunopathol 2012, 145:571-581.

37. Hoof I, Peters B, Sidney J, Pedersen LE, Sette A, Lund O, Buus S, Nielsen M: NetMHCpan, a method for MHC class I binding prediction beyond humans. Immunogenetics 2009, 61:1-13.

38. NetMHCpan 2.8. [http://www.cbs.dtu.dk/services/NetMHCpan-2.8/]

39. Thomsen M, Lundegaard C, Buus S, Lund O, Nielsen M: MHCcluster, a method for functional clustering of MHC molecules. Immunogenetic 2013, 65:655-665. 
40. Robinson J, Halliwell JA, McWilliam H, Lopez R, Parham P, Marsh SG: The IMGT/HLA database. Nucleic Acids Res 2013, 41:D1222-D1227.

41. Robinson J, Halliwell JA, McWilliam H, Lopez R, Marsh SG: IPD-the Immuno Polymorphism Database. Nucleic Acids Res 2013, 41:D1234-D1240.

42. Robinson J, Waller MJ, Fail SC, Marsh SG: The IMGT/HLA and IPD databases. Hum Mutat 2006, 27:1192-1199.

43. Li X, Liu J, Qi J, Gao F, Li Q, Li X, Zhang N, Xia C, Gao GF: Two distinct conformations of a rinderpest virus epitope presented by bovine major histocompatibility complex class I N*01801: a host strategy to present featured peptides. J Virol 2011, 85:6038-6048.

44. Akoolo L, Pelle R, Saya R, Awino E, Nyanjui J, Taracha EL, Kanyari P, Mwangi DM, Graham SP: Evaluation of the recognition of Theileria parva vaccine candidate antigens by cytotoxic T lymphocytes from Zebu cattle. Vet Immunol Immunopathol 2008, 121:216-221.

45. NetMHCpan 2.4. [http://www.galvmed.org/2012/03/east-cost-fever-vaccinelaunch-arusha-tanzania/]

46. Hirano A, Brown WC, Trigona W, Tuo W, Estes DM: Kinetics of expression and subset distribution of the TNF superfamily members CD40 ligand and Fas ligand on T lymphocytes in cattle. Vet Immunol Immunopathol 1998, 61:251-263.

47. Hogg AE, Parsons K, Taylor G, Worth A, Beverley P, Howard CJ, VillarrealRamos B: Characterization of age-related changes in bovine CD8+ T-cells. Vet Immunol Immunopathol 2011, 140:47-54

48. Emery DL, Eugui EM, Nelson RT, Tenywa T: Cell-mediated immune responses to Theileria parva (East Coast fever) during immunization and lethal infections in cattle. Immunology 1981, 43:323-336.

49. Emery DL, Kar SK: Immune responses of cattle to Theileria parva (East Coast fever): specificity of cytotoxic cells generated in vivo and in vitro. Immunology 1983, 48:723-731.

50. McKeever DJ, Taracha EL, Innes EL, MacHugh ND, Awino E, Goddeeris $B M$, Morrison WI: Adoptive transfer of immunity to Theileria parva in the CD8+ fraction of responding efferent lymph. Proc Natl Acad Sci USA 1994, 91:1959-1963.

51. MHCcluster. [http://www.cbs.dtu.dk/services/MHCcluster-2.0]

52. Thomsen MC, Nielsen M: Seq2Logo: a method for construction and visualization of amino acid binding motifs and sequence profiles including sequence weighting, pseudo counts and two-sided representation of amino acid enrichment and depletion. Nucleic Acids Res 2012, 40:W281-W287.

53. Zhang L, Udaka K, Mamitsuka H, Zhu S: Toward more accurate panspecific MHC-peptide binding prediction: a review of current methods and tools. Brief Bioinform 2012, 13:350-364.

54. Zhang $\mathrm{H}$, Lund $\mathrm{O}$, Nielsen M: The PickPocket method for predicting binding specificities for receptors based on receptor pocket similarities: application to MHC-peptide binding. Bioinformatics 2009, 25:1293-1299.

55. Tenaya IW, Heel K, Stumbles PA, Wilcox GE: Flow cytometric analysis of lymphocyte subset kinetics in Bali cattle experimentally infected with Jembrana disease virus. Vet Immunol Immunopathol 2012, 149:167-176.

doi:10.1186/1297-9716-45-50

Cite this article as: Svitek et al:: Use of "one-pot, mix-and-read" peptide-MHC class I tetramers and predictive algorithms to improve detection of cytotoxic T lymphocyte responses in cattle. Veterinary Research 2014 45:50.

\section{Submit your next manuscript to BioMed Central and take full advantage of:}

- Convenient online submission

- Thorough peer review

- No space constraints or color figure charges

- Immediate publication on acceptance

- Inclusion in PubMed, CAS, Scopus and Google Scholar

- Research which is freely available for redistribution 